\title{
Effect of Cu on Hydrogen Permeation for the Low Carbon Steel under Mildly Sour Environments
}

\author{
Haruo Nakamichi ${ }^{1}$, Kazuhiko Baba ${ }^{1}$, Daisuke Mizuno ${ }^{2}$, Kyono Yasuda $^{3}$ and Nobuyuki Ishikawa ${ }^{3}$ \\ 1. Analysis \& Characterization Res. Dept., Steel Res. Lab., JFE Steel Corp., Kawasaki, Japan. \\ 2. Material Surface \& Interface Science Res. Dept., Steel Res. Lab., JFE Steel Corp., Kawasaki, Japan. \\ 3. Steel Products Res. Dept. Steel Res. Lab., JFE Steel Corp., Fukuyama, Japan.
}

Hydrogen Induced Cracking (HIC) and Sulfide Stress Cracking (SSC) are the major issue for low carbon alloyed steels applied to sour line pipes at oil and natural gas fileds. It is caused by the presence of hydrogen sulfide, which enhances hydrogen entry into steels and causes the environmental cracking. It is well known that $\mathrm{Cu}$ is effective element for preventing $\mathrm{HIC}$ in mildly sour environments in which the solution $\mathrm{pH}$ is more than 5.0[1]. However, the mechanism of $\mathrm{Cu}$ rolls on HIC prevention has not been fully clarified. It was found that $\mathrm{Cu}$ addition remarkably decreased hydrogen entry into steel[2] and $\mathrm{Cu}$ was enriched in the corrosion product based on EPMA micron order analysis [3]. In present paper, corrosion test under $\mathrm{H}_{2} \mathrm{~S}$ environments are carried out with measuring the amount of hydrogen permeation. Microstructural morphologies of corrosion products, especially $\mathrm{Cu}$ distribution and morphologies are investigated through FIB/SEM and STEM analysis for understanding its rolls on preventing the corrosions.

Two samples, concentration of $0.06 \mathrm{C}-1.7 \mathrm{Mn}-0.1 \mathrm{Si}$ with and without $0.3 \mathrm{wt} \% \mathrm{Cu}$, were prepared through a vacuum melting. Corrosion tests were performed under $100 \% \mathrm{H}_{2} \mathrm{~S}$ gas environment in $5 \% \mathrm{NaCl}+1 \mathrm{~N}(\mathrm{CH} 3 \mathrm{COOH}+\mathrm{CH} 3 \mathrm{COONa})$ solution for $96 \mathrm{hrs}$. The hydrogen permeation was measuring during corrosion test. For evaluating effects of solution environment on corrosion product, two $\mathrm{pH}$ conditions of 5.0 and 5.3 were performed. After corrosion test, samples were picked up from the solution and SEM and TEM observations were carried out. Cross section samples of SEM and TEM were prepared by FIB techniques. Distribution of alloy elements in the corrosion product and steel were measured through EDS analysis equipped with SEM and TEM

Fig. 1 shows plane view SEM images of corrosion product of $\mathrm{Cu}$ added steel immersed in the $\mathrm{pH} 5.3$ and 5.0 solutions. It is observed that the surface morphology of corrosion products formed in high $\mathrm{pH}$ solution were smooth compared with that of in low $\mathrm{pH}$ solution. Micrographs of SEM cross sectioning are show in Fig. 2, together with the hydrogen permeation value at 90 hours of corrosion test. Several micro-meter thickness of corrosion product is formed during immersion test and there are roughly two layers in that product. Different microstructure is recognized dependent on the $\mathrm{Cu}$ concentration and $\mathrm{pH}$ value. The upper layer formed on the $\mathrm{Cu}$ added steel in high $\mathrm{pH}$ solution is uniform even though it structure is porous. On the other hand, that of formed on non- $\mathrm{Cu}$ added steel in low $\mathrm{pH}$ solution is very rough and has many large cracks. The bottom layer formed on the $\mathrm{Cu}$ added steel in high $\mathrm{pH}$ solution has dense structure and no cracks. The hydrogen permeated value is increasing when the corrosion layer has large cracks. It is supposed that adding $\mathrm{Cu}$ is very useful for forming uniform tight corrosion layer without large cracks for preventing hydrogen permeation. For evaluating the $\mathrm{Cu}$ distribution in the corrosion film, cross sectional TEM analysis is carried out and the STEM images shown in Fig.3. It is found that the small crystal size of FeS ( less than 10nm) is formed at the bottom layer of corrosion products from electron diffraction analysis. The upper layer of corrosion products has bigger crystal 
size and has many pores. EDS mapping results of $\mathrm{Cu}$ in the corrosion layer is shown in Fig.4. Thickness of $\mathrm{Cu}$ enriched layer is about 100nm. This tiny $\mathrm{Cu}$ layer would prevent the hydrogen permeation and form a tighten corrosion layer in $\mathrm{pH} 5.3$ solution. Based on SEM cross section result (Fig.2), this $\mathrm{Cu}$ layer effectiveness for preventing hydrogen permeation is decreasing under $\mathrm{pH} 5.0$ solution because of less of uniformity of bottom corrosion layer in this case. It is suggested that the formation of this tight layer is very important for preventing HIC for preventing hydrogen immersion and $\mathrm{Cu}$ adding is enhancing to form this layer.

\section{References:}

[1] Y. Inohara et. al., Proceedings of 13th ISOPE, USA (2003) paper no. Symp-05.

[2] Y. Nakai, H. Kurahashi, N. Totsuka and Y. Uesugi, Corrosion/82, (1982) paper no.132

[3] T. Hara and H. Asahi, Proc. Pipeline Technology Conf., (2004)
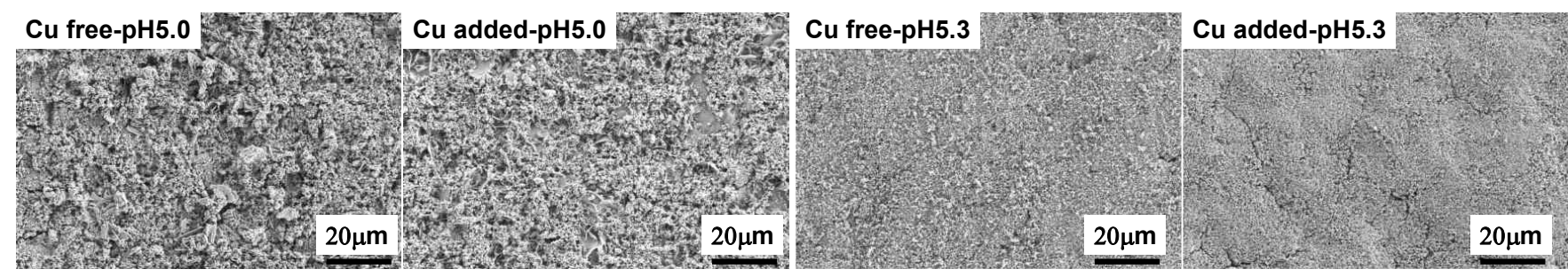

Figure 1. SEM plan view of corrosion product
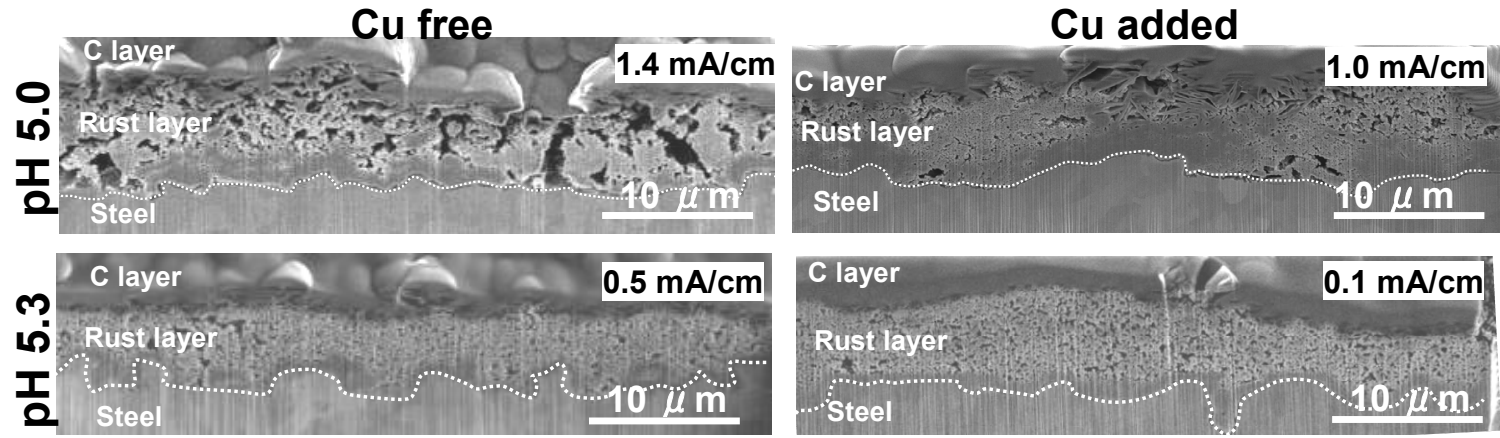

Figure 2. SEM cross sectional view of corrosion product

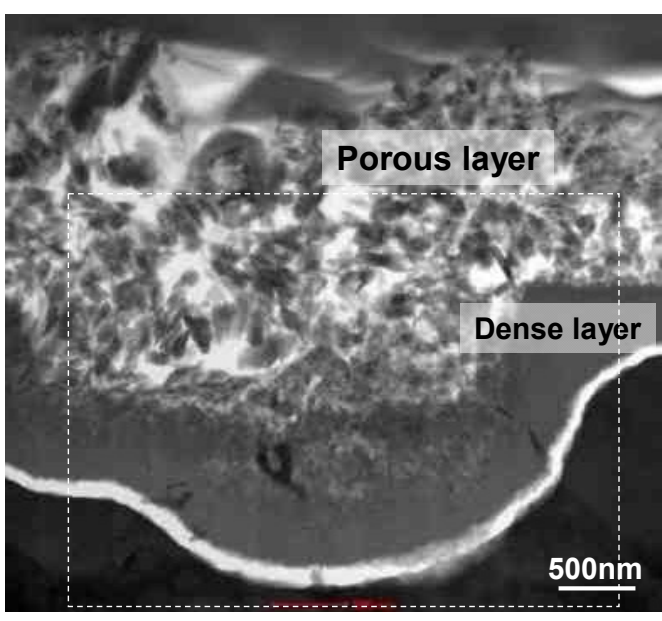

Figure 3. STEM image of corrosion product of $\mathrm{Cu}$ added steel in pH5.3 sample

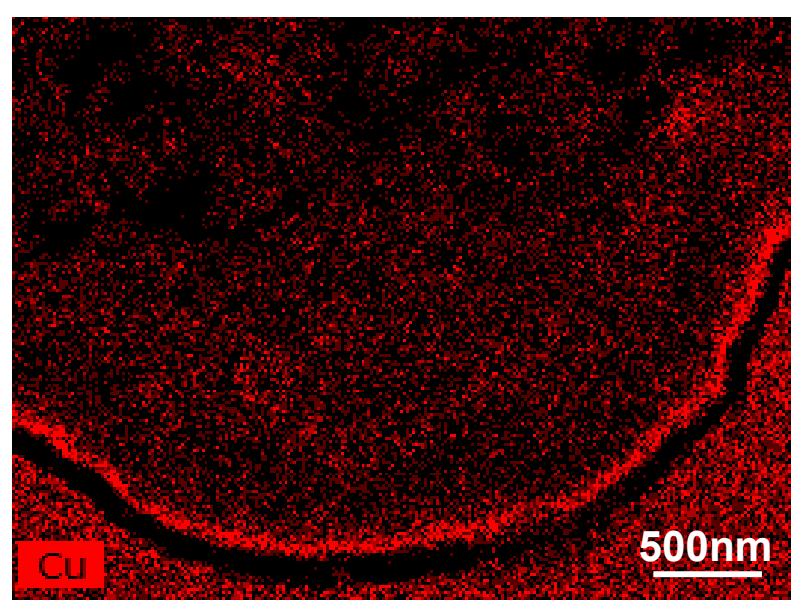

Figure 4. STEM-EDS mapping of $\mathrm{Cu}$ in the indicated area of figure 3 